\title{
Crónica
}

\section{Debate sobre el aborto se toma la agenda política de varios países}

\begin{abstract}
Europa vive dos flancos respecto de la interrupción del embarazo debido a leyes que la limitan en España y que la amplían en Francia. El tema ha vuelto a la discusión en EE.UU., donde se aprobaron 53 restricciones estatales contra el aborto durante 2013.
\end{abstract}

Belén Miranda - 25/01/2014. Disponible en: http://www.latercera.com/noticia/mundo/2014/01/678-562456-9-debate-sobre-el-aborto-se-toma-la-agenda-politica-de-varios-paises.shtml

Durante los últimos meses, el debate sobre el aborto ha regresado con fuerza a la palestra mundial de la mano de países como España, Francia y Estados Unidos. Así, mientras el gobierno español impulsa la aprobación de un proyecto de ley que ha generado controversia y que propone limitar los supuestos en que las mujeres puedan abortar, al otro lado de la frontera, su vecino, Francia, camina en dirección opuesta, con la reciente aprobación de una enmienda que elimina cualquier condición previa para someterse a un aborto. Si bien esta práctica está permitida desde hace 41 años en Estados Unidos, recientemente varios estados del país han cerrado filas en torno a una postura más restrictiva respecto de la interrupción del embarazo.

De hecho, entre 2011 y 2013, en Estados Unidos se promulgaron más restricciones contra el aborto que en toda la década previa. Así, sólo en 2013 se aprobaron 53 restricciones, de acuerdo con el diario estadounidense The Washington Post. A esto se suma el cierre de varios centros sanitarios que realizan abortos por no cumplir las normativas estatales. Una situación graficada por las cifras, ya que desde 1991 a 2011 las clínicas que se dedican a la práctica del aborto han disminuido de 2.200 a 678 , de acuerdo con The Wall Street Journal.

Esta discusión ha llevado a que, por ejemplo, el Partido Republicano -la mayoría de cuyos miembros aboga por restringir el aborto- ponga al tema como uno de los principales de su agenda. De hecho, el miércoles, el mismo día que se celebraba la marcha por la vida en Washington, el Comité Nacional Republicano se reunió para considerar una resolución que permitiría a sus candidatos hablar abiertamente sobre posturas antiabortistas con el fin de obtener un mayor apoyo popular, según apunta el Post. "No es probable que tenga los efectos beneficiosos que sus promotores están buscando. Sólo servirá para aumentar las divisiones dentro del Partido Republicano entre los llamados moderados y los llamados conservadores", indicó a La Tercera el analista estadounidense William B. Allen. Según un sondeo elaborado por The Washington Post, un $56 \%$ de los norteamericanos apoya limitar los abortos después de las primeras 20 semanas de embarazo, en lugar de las 24 establecidas por ley.

En un camino diferente transita el Presidente Barack Obama, quien defendió su compromiso con la postura pro aborto, tal como lo afirmó durante su campaña para la reelección en 2012. "Reafirmamos nuestro firme compromiso con la protección del acceso de la mujer a la atención médica económica y segura, su derecho constitucional a la privacidad, incluyendo el derecho a la libertad reproductiva", dijo el mandatario esta semana, con motivo del aniversario número 41 del fallo que declaró legal las prácticas de interrupción del embarazo en el país.

Al otro lado del océano Atlántico, el tema del aborto ha copado las portadas de la prensa española a raíz del anteproyecto de ley del gobierno que busca modificar la actual ley de plazos, vigente desde 2010 y que permite el aborto dentro de las 14 primeras semanas de gestación, por una en que sólo la interrupción será legal en caso de una violación en las primeras 12 semanas de embarazo o que exista riesgo para la salud de la madre en las primeras 22 semanas, excluyendo el supuesto de anomalías fetales.

"El aborto es un tema enormemente sensible y con esa sensibilidad y delicadeza debe tratarse", 
indicó esta semana el jefe del ejecutivo español, Mariano Rajoy, quien reconoció por primera vez que la iniciativa tiene "puntos sin duda controvertidos". Si la ley entra en vigor, España quedaría a la par de otros países europeos que mantienen leyes más estrictas para regular el aborto, como Polonia e Irlanda. Este último país cuenta, por primera vez, desde el 1 de enero, con una ley que permite esta práctica en situaciones en que la vida de la madre corre "un riesgo real y sustancial", lo que también incluye el riesgo de suicidio que debe ser médicamente probado.

Francia vive otro panorama. La Asamblea Nacional aprobó el martes una enmienda que elimina de la ley de aborto de 1975 la referencia "situación de desamparo", que condicionaba a la mujer a argumentar esta noción para llevarlo a cabo, dejando la vía más libre a las interrupciones voluntarias de embarazo. Esta ampliación del aborto se suma a la iniciativa que, desde enero de 2013, obliga a la Seguridad Social a reembolsar totalmente el procedimiento.

De acuerdo con datos citados por la agencia France Presse, cerca de 220.000 abortos se producen en Francia anualmente. En España, en tanto, se practicaron 112.390 abortos en 2012, una disminución del 5\% respecto de los 118.259 que se llevaron a cabo en 2011, según indicó el Ministerio de Sanidad español.

Pero el gobierno galo -que fue un crítico del proyecto de Rajoy- también quiere ampliar el delito para quienes pongan trabas para acceder al aborto, lo que tampoco ha estado exento de críticas. Así, el ex primer ministro conservador Francois Fillon dijo que el Ejecutivo del Presidente Francois Hollande había cometido una "falta moral y política" que podría "dividir una vez más a los franceses". 